\title{
Industrial Yogurt Manufacture: Monitoring of Fermentation Process and Improvement of Final Product Quality
}

\author{
C. Soukoulis, ${ }^{*}$ P. Panagiotidis, ${ }^{*}$ R. Koureli, $\dagger$ and C. Tzia*1 \\ *Laboratory of Food Chemistry and Technology, School of Chemical Engineering, National Technical University of Athens, \\ Polytechnioupoli Zografou, Athens, Greece \\ †Fage S. A., Ermou 35 str., Metamorfosi, Athens, Greece
}

\begin{abstract}
Lactic acid fermentation during the production of skim milk and whole fat set-style yogurt was continuously monitored by measuring $\mathrm{pH}$. The modified Gompertz model was successfully applied to describe the $\mathrm{pH}$ decline and viscosity development during the fermentation process. The viscosity and incubation time data were also fitted to linear models against $\ln (\mathrm{pH})$. The investigation of the yogurt quality improvement practices included 2 different heat treatments $\left(80^{\circ} \mathrm{C}\right.$ for 30 min and $95^{\circ} \mathrm{C}$ for $10 \mathrm{~min}$ ), 3 milk protein fortifying agents (skim milk powder, whey powder, and milk protein concentrate) added at $2.0 \%$, and 4 hydrocolloids ( $\kappa$-carrageenan, xanthan, guar gum, and pectin) added at $0.01 \%$ to whole fat and skim yogurts. Heat treatment significantly affected viscosity and acetaldehyde development without influencing incubation time and acidity. The addition of whey powder shortened the incubation time but had a detrimental effect on consistency, firmness, and overall acceptance of yogurts. On the other hand, addition of skim milk powder improved the textural quality and decreased the vulnerability of yogurts to syneresis. Anionic stabilizers ( $\kappa$-carrageenan and pectin) had a poor effect on the texture and palatability of yogurts. However, neutral gums (xanthan and guar gum) improved texture and prevented the wheying-off defect. Skim milk yogurts exhibited longer incubation times and higher viscosities, whereas they were rated higher during sensory evaluation than whole fat yogurts.
\end{abstract}

Key words: yogurt fermentation monitoring, heat treatment, stabilizer, protein fortifier

\section{INTRODUCTION}

\section{Improvement of the Quality Characteristics of Yogurt}

Flavor and texture are the most pronounced factors that influence the quality and acceptance of yogurt and

Received December 1, 2006.

Accepted January 29, 2007.

${ }^{1}$ Corresponding author: tzia@chemeng.ntua.gr related fermented milks. Many parameters affect flavor, body, and texture of yogurt such as the starter culture, incubation temperature, processing conditions (e.g., heat treatment, homogenization) and compositional properties of the milk base (Labropoulos et al., 1984; Tamime and Robinson, 1999; Shaker et al., 2001; Hassan et al., 2003).

Milk heat treatment is considered to be a critical factor for texture formation. Heating induces whey protein denaturation so that whey proteins can associate with casein micelles. Whey proteins are bound to caseins through disulfide linkages and hydrophobic interactions (Law, 1996). The application of a time-temperature profile ranging from 8 to $85^{\circ} \mathrm{C}$ for $30 \mathrm{~min}$ to 90 to $95^{\circ} \mathrm{C}$ for $5 \mathrm{~min}$ is regarded to be adequate for producing high quality yogurt (Lucey and Singh, 1997). Lucey et al. (1997) reported that the increase of heating intensity induced an extensive denaturation of whey proteins (primarily $\beta$-LG), which in turn was correlated to increased storage modulus $\left(\mathbf{G}^{\prime}\right)$ during acid gelation. Lucey et al. (1999) reported that gelation commences earlier in severely heat-treated milks, leading to a significant decrease of the coagulation time of directly acidified milks. In general, an increase in denaturation of whey proteins (primarily of $\beta$-LG) leads to a reduction in fermentation times (Labropoulos et al., 1984; Parnell-Clunies et al., 1986; Thomopoulos et al., 1993, Shaker et al., 2000). However, yogurt prepared with unheated or inadequately heat-treated milk, is characterized by poor texture, weak gel and firmness, and increased susceptibility against wheying off (Tamime and Robinson, 1999).

Fortification of solid matter can be achieved by using several materials including skim milk powder (SMP), milk protein concentrates (MPC), whey protein concentrates (WPC), and caseinates. Schkoda et al. (2001) reported that the firmness and the resistance of yogurt gels against syneresis are improved as the protein content increases. Dave and Shah (1998) and Bhullar et al. (2002) demonstrated that WPC addition favors firmness and viscosity of yogurt whereas whey powder (WP) seems to be insufficient to improve its quality 
profile. Puvanenthiran et al. (2002) investigated the effect of substituting SMP with WPC added in different ratios and concluded that the increase of the whey to casein ratio was associated with the increase of fermentation time, $\mathrm{pH}$ of gelation, and firmness, whereas the syneresis defect was constrained. Guzman-Gonzalez et al. (1999, 2000) studied many protein ingredients including SMP, WPC, caseinates, and dairy blends and observed that the addition of caseinates significantly improved firmness and syneresis prevention, whereas WPC, although it controlled wheying loss, did not enhance texture. Generally, the addition of $2 \%$ of protein concentrates is considered adequate for amending the textural quality of yogurt (Tamime and Robinson, 1999).

The addition of hydrocolloids is another way to increase firmness and viscosity of yogurt. The functionality of hydrocolloids is demonstrated by their ability to bind water, react with the milk constituents (mainly proteins), and stabilize the protein network, preventing free movement of water (Tamime and Robinson, 1999). Ramaswamy and Basak (1992) observed significant improvement of the rheological profile of flavored yogurt when 0.3 to $0.4 \%$ pectin was added. Gelatin is one of the most preferable stabilizers for use in fermented milks. Fiszman and Salvador (1999) and Fiszman et al. (1999) reported that gelatin over a great range of concentrations was able to improve the rheological and textural properties of skim yogurt and to hinder the syneresis defect. Keogh and O'Kennedy (1998) reported that gelatin, xanthan, and locust bean increased the consistency of stirred yogurt, whereas the addition of wheat starch did not. $\kappa$-Carrageenan has also been investigated for its action in acidified milks. Kalab et al. (1975) reported that $\kappa$-carrageenan creates long, thin fibers connected with clusters of $\kappa$-CN micelles, whereas Baeza et al. (2002) reported that in the presence of $\kappa$-carrageenan and denaturated proteins, increases in hardness, adhesiveness, gumminess, and cohesiveness of gels occurred.

\section{Online Monitoring of the Fermentation Process}

The determination of incubation time is an essential technical parameter in industrial yogurt production. Due to the complexity of the fermentation process and the great number of factors entangled in yogurt coagulation, prediction of the incubation step is difficult, so it is a common practice to control it empirically. In addition, definition of the optimal incubation time is significant not only in reducing the manufacturing cost but also in avoiding deterioration of the quality characteristics of the final product.
The end point of the fermentation process is usually defined by the $\mathrm{pH}$ value. When the $\mathrm{pH}$ end point is specified, by means of the final product quality profile, then online control of the fermentation process can be carried out by monitoring $\mathrm{pH}$. De Brabandere and De Baerdemaeker (1999) suggested the continuous control of the fermentation process by monitoring $\mathrm{pH}$. The advantages of this method include low investment and functional cost, easy implementation, and absence of any fluctuations of yogurt coagulation. Alternatively, Navratil et al. (2004) and Cimander et al. (2002) proposed the online monitoring of yogurt fermentation through the implementation of near infrared (NIR) and electronic nose techniques combined.

The aims of our study were 1) to investigate the applicability of continuous $\mathrm{pH}$ monitoring for controlling the fermentation process and predicting the quality characteristics of the final product and 2) to study the effects of processing parameters (heat treatment) and compositional properties of milk base such as milk fat, milk solids-not-fat (MSNF) fortifiers, and hydrocolloids, on the incubation time and textural, chemical, and sensory properties of set-style yogurts.

\section{MATERIALS AND METHODS}

\section{Preparation of Milk Base}

Whole (3.5\% fat, $8.7 \% \mathrm{MSNF})$ and skim (0.03\% fat, 8.6\% MSNF) homogenized milk was obtained from a local dairy plant (Fage S.A., Athens, Greece). Milk was divided into 3 batches. Two batches were supplemented either with stabilizers or dairy ingredients respectively, whereas the third batch had no additions. Skim milk powder, MPC, and WP (EPI Ingredients, Ancenis, France) were added at the level of $2 \%$ for elevating milk solids content. Four hydrocolloids (methylopectin, guar gum, $\kappa$-carrageenan, and xanthan) were used at $0.01 \%$ (Chimicotechniki S.A., Athens, Greece). Protein solids and stabilizers were dispersed under turbulent agitation in milk heated to $50^{\circ} \mathrm{C}$. The fortified milk was subjected, by means of a circulating water bath, to 2 different heat treatments: $80^{\circ} \mathrm{C}$ for $30 \mathrm{~min}$ or $95^{\circ} \mathrm{C}$ for $10 \mathrm{~min}$. Sample preparation was duplicated giving a total of 56 formulations. The codification used for the description of the samples is cited in Table 1.

\section{Preparation of Yogurt}

The pasteurized milk bases were cooled to incubation temperature, inoculated with a mixed lactic starter (1:1 Streptococcus salivarius ssp. thermophilus and Lactobacillus delbrueckii ssp. bulgaricus) at selected concentrations, poured into $300-\mathrm{mL}$ plastic containers, and incubated at $45^{\circ} \mathrm{C}$. The size of the inoculum was set at 
Table 1. Definitions of the descriptors (sensory attributes) used for evaluation of the yogurts

\begin{tabular}{|c|c|}
\hline Attribute & Description \\
\hline Color & Assess the color (white, whitish, yellowish, yellow) of yogurt \\
\hline Firmness & Estimate the hardness, brittleness, gumminess, and gelatin-like texture of the coagulum \\
\hline Consistency & $\begin{array}{l}\text { Evaluate the viscosity when stirring the product with the spoon; determine of the rheological behavior of } \\
\text { yogurt in the mouth }\end{array}$ \\
\hline Syneresis & Visual observation of the yogurt surface; examine whey drainage after inserting the spoon into the curd \\
\hline Overall acceptance & Rate the overall score of the sample considering the appearance, taste, and flavor profiles \\
\hline
\end{tabular}

$2.5 \%(\mathrm{wt} / \mathrm{wt}$ ). The coagulation of milk was monitored for $\mathrm{pH}$ during the incubation period until a $\mathrm{pH}$ of 4.4 was attained (the $\mathrm{pH}$ end point). The $\mathrm{pH}$ meter was connected to a computer recorder and $\mathrm{pH}$ was continuously recorded as a function of time (s) to obtain sigmoidal curves representing the fermentation process. Acidity and apparent viscosity determination was conducted at fixed time intervals during the incubation of yogurt. When the $\mathrm{pH}$ end point was achieved, the yogurts were cooled at $7^{\circ} \mathrm{C}$, stored at the same temperature for 24 $\mathrm{h}$, and then acetaldehyde and sensory analyses were conducted. Sensory evaluation was conducted only on the samples heat treated at $95^{\circ} \mathrm{C}$.

\section{Measurement of $\mathrm{pH}$}

pH was measured using a pH meter (WTW-pH 330, Weilheim, Germany) with a glass electrode standardized at $45^{\circ} \mathrm{C}$ over the range 6.8 to 4.0 .

\section{Measurement of Viscosity}

Apparent viscosity (expressed in cPs) was measured using a Brookfield viscometer model LV (Brookfield Engineering Laboratories Inc., Stoughton, MA) using a helipath stand at $30 \mathrm{rpm}$ with T-bar spindle C. For each sample, 3 dial readings were taken at 30 -s intervals and their mean value was reported. Viscosity measurements were performed in yogurts at the incubation temperature, which was maintained by a circulating water bath.

\section{Determination of Acidity}

Acidity was determined in duplicate by titration with $0.1 \mathrm{~N} \mathrm{NaOH}$ using phenolophthalein as indicator. Results were expressed as grams of lactic acid per one hundred grams of yogurt.

\section{Determination of Acetaldehyde}

Acetaldehyde concentration was determined enzymatically adapting the aldehyde dehydrogenase method (Mannheim Boehringer GmbH, 1987). Results were expressed in milligrams of acetaldehyde per one hundred grams of yogurt.

\section{Sensory Evaluation}

Eight panelists experienced in the evaluation of fermented dairy products were chosen for the assessment of the sensory attributes of yogurt samples. Flavor, texture, and appearance of the samples were evaluated. A predetermined list of 18 sensory attributes was used to describe the sensory characteristics of yogurts (Bodyfelt et al., 1988; Hui, 1993; Martin et al., 1999; Tamime and Robinson, 1999). A 2-h training session was conducted to evaluate the use of the attributes by the panelists during sensory analysis. Panelists' training was carried out using one standard for each sensory attribute prepared according to the procedures described by Hui (1993). The introduced sensory attributes allowed the differentiation of samples in terms of appearance (color), texture (firmness, consistency, syneresis), flavor (flavor and aroma), and taste (palatability).

Samples were coded using a 3-digit random number and served successively to the panelists in individually partitioned booths. Samples were tempered at $7^{\circ} \mathrm{C}$ for $24 \mathrm{~h}$ before sensory assessment. Samples were served in 125-g plastic cups. All of the sensory attributes assessed by the panelists were rated using a 10-point scale ( $1=$ unacceptable, $5=$ acceptable, $10=$ no criticism). The assessment procedure of the sensory attributes of yogurts was divided into 3 major stages. First, flavor was assessed by removing the lid of the cup and rating the intensity of the volatile flavor substances (e.g., lactic acid and acetaldehyde). Second, appearance by visual observation and textural properties by breaking down the yogurt gel and agitating the product were evaluated. Finally, the taste and aroma (aroma sensory attribute was defined as the combined perception of the detected aroma defects) of yogurts was assessed by swallowing $10 \mathrm{~g}$ (a teaspoon portion) of sample. Overall acceptance was rated at the end of the sensory evalua- 
tion of each sample. The sensory attributes and their descriptions used for the characterization of yogurts are given in Table 1. Panelists were motivated to note any criticisms on the score sheets used for the sensory evaluation.

\section{Experimental Designs}

A 3-way factorial design, with heat treatment (2 levels), milk fat content (2 levels), and addition type (8 levels including control samples; 3 protein fortifiers, 4 hydrocolloids, and 1 with no additions) as the main effects, was applied to investigate their effects on the fermentation progress physicochemical properties (incubation time, viscosity, acidity, and acetaldehyde). Two 2-way factorial designs with milk fat content (2 levels) as the first main effect and hydrocolloid type (5 levels including control samples) or MSNF fortifier (4 levels including control samples) as the second main effect were implemented to study their impact on the sensory properties. The latter experimental designs were also used to reveal the specific effects of hydrocolloids and MSNF fortifying agents on the physicochemical properties.

\section{Statistical Analyses}

All of the statistical analyses were performed using Statistica software (Statistica 7.0, StatSoft Inc., Tulsa, OK). Significant differences were defined at $P<0.05$. The ANOVA for each assessor was used to verify their ability to replicate their results within repeated sessions. An ANOVA was also performed to evaluate the main effects and interactions of heat treatment, milkfat, hydrocolloids, and MSNF sources on the physicochemical and sensory data. Multiple mean comparisons were carried out by performing Duncan's least significance difference. Principal components analysis (PCA) was applied to physicochemical and sensory data means.

\section{RESULTS AND DISCUSSION}

\section{Online Monitoring of Fermentation Process}

The $\mathrm{pH}$ profiles of yogurts prepared with skim or whole milk are shown in Figure 1. As expected, 3 phases described the entire fermentation process: 1) lag phase (slow $\mathrm{pH}$ decline), 2) logarithmic phase (rapid $\mathrm{pH}$ decrease), and 3) slow down of acidification rate. The shape of fermentation curve is strictly dependent on many parameters including the milk base, the type and concentration of supplemented ingredients, starter culture, incubation temperature, and milk heat treatment. Figure 1 shows that in whole milk fermentation, the

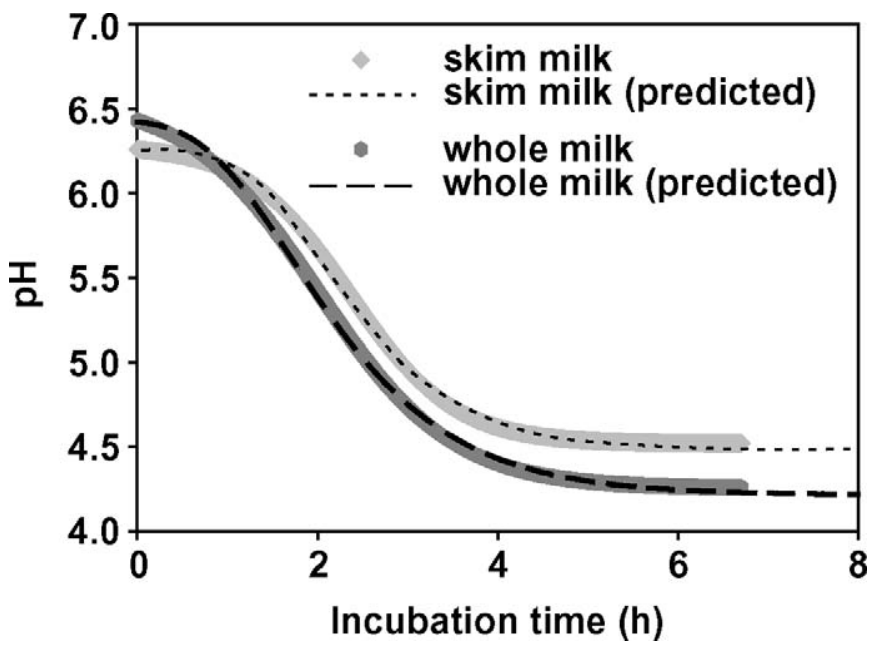

Figure 1. Profiles of $\mathrm{pH}$ and incubation during the lactic acid fermentation of whole and skim milk.

lag phase was shorter and the $\mathrm{pH}$ decline was steeper compared with acidified skim milk. De Brabandere and De Baerdemaeker (1999) reported that despite the shape, $\mathrm{pH}$ profiles with incubation time could be described by the modified Gompertz equation for bacterial growth:

$$
\begin{gathered}
p H=p H_{0}+\left(p H_{\infty}-p H_{0}\right) \\
\exp \left\{-\exp \left[\frac{\mu e}{\left(p H_{\infty}-p H_{0}\right)}(\lambda-t)+1\right]\right\},
\end{gathered}
$$

where $\mathrm{pH}_{0}=$ initial $\mathrm{pH}, \mathrm{pH}_{\infty}=$ final $\mathrm{pH}, \mu=$ maximum $\mathrm{pH}$ reduction rate, and $\lambda=$ lag phase time.

Our results confirmed the former dependence of $\mathrm{pH}$ vs. incubation time. The calculated parameters according to the previous mathematical model are given in Table 2.

Viscosity monitoring can be carried out in a similar way to $\mathrm{pH}$ screening; for example, by continuous measurement of rheological properties using rotational or oscillatory rheometers (Shaker et al., 2000, 2001).

Apparent viscosity development can also be described using the modified Gompertz model:

$$
\begin{gathered}
\mu_{a}=\mu_{a_{0}}+\left(\mu_{a_{0}}-\mu_{a_{\infty}}\right) \\
\exp \left\{-\exp \left[\frac{\mu e}{\left(\mu_{a_{0}}-\mu_{a_{\infty}}\right.}(\lambda-t)+1\right]\right\},
\end{gathered}
$$

where $\mu_{a}=$ apparent viscosity, $\mu_{\mathrm{a}_{0}}=$ initial apparent viscosity, $\lambda=$ lag phase time, and $\mu=$ maximum rate of apparent viscosity. 
Table 2. Effects of milk fat on the lag phase time $(\lambda)$, maximum rate of $\mathrm{pH}$ reduction $(\mu)$, initial $\mathrm{pH}\left(\mathrm{pH}_{0}\right)$, and $\mathrm{pH}$ end point $\left(\mathrm{pH}_{\infty}\right)$

\begin{tabular}{lrr}
\hline & \multicolumn{2}{c}{ Type of milk } \\
\cline { 2 - 3 } Parameter & \multicolumn{1}{c}{ Skim } & Whole \\
\hline$\lambda(\mathrm{h})$ & 1.1930 & 0.7089 \\
$\mu\left(\mathrm{h}^{-1}\right)$ & -0.7758 & -0.8121 \\
$\mathrm{pH}_{\infty}-\mathrm{pH}_{0}$ & -1.7745 & -2.2176 \\
$\mathrm{pH}_{0}$ & 6.2595 & 6.4308 \\
\hline
\end{tabular}

Figure 2 illustrates the profiles of viscosity vs. incubation time. Apparent viscosity development can be also described using the modified Gompertz model [Eq. 2]. Regression coefficients were found to be adequate for both yogurt formulations $\left(\mathrm{R}^{2}=0.978\right.$ for whole and 0.938 for skim milk yogurt). The parameters estimated according to the Gompertz model are given in Table 3. It is well established that viscosity development is strictly related to the coagulation phenomena and gel formation and consequently to the biochemical and
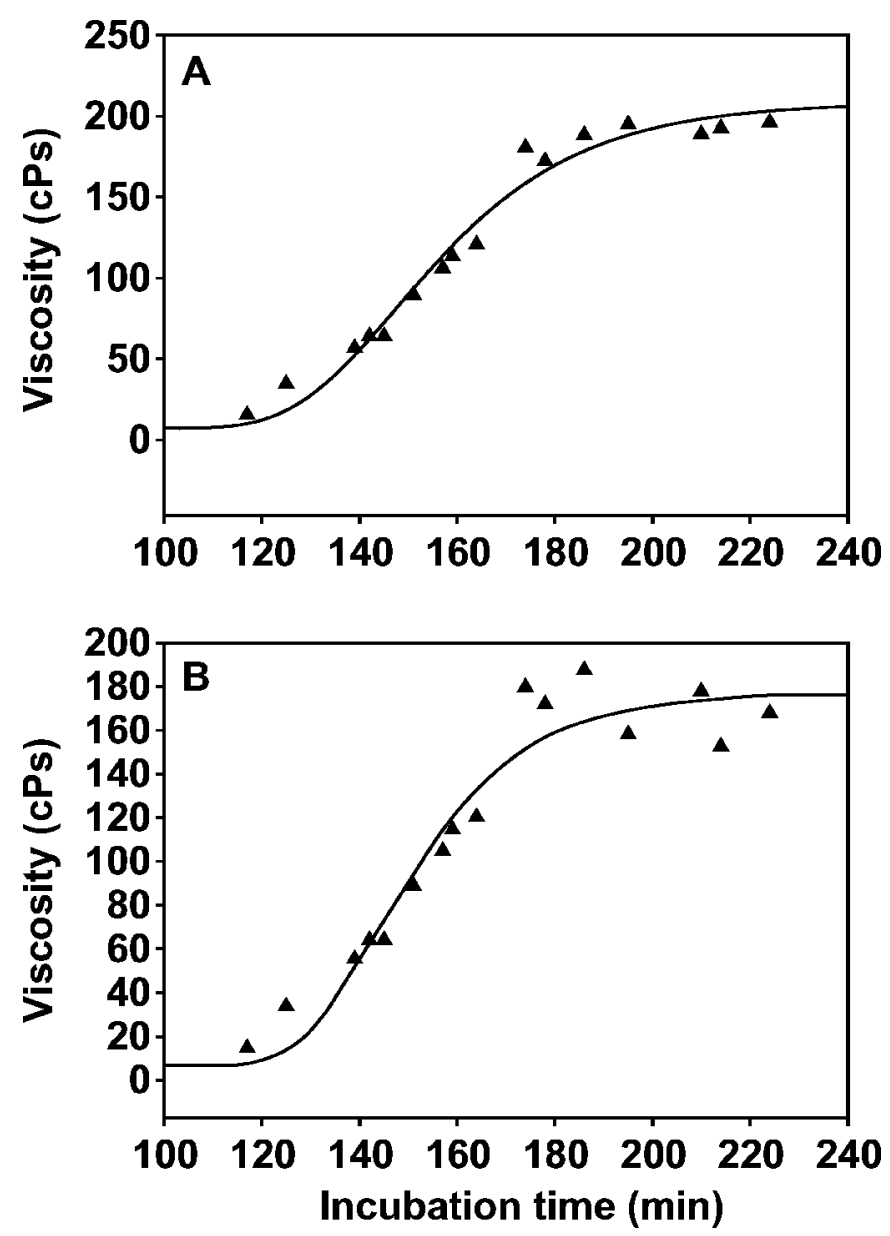

Figure 2. Viscosity-incubation time profiles during the lactic acid fermentation of A) whole and B) skim milk.
Table 3. Effects of milk fat on the lag phase time $(\lambda)$, maximum rate of apparent viscosity development $(\mu)$, initial apparent viscosity $\left(\mu_{\mathrm{a} 0}\right)$, and final apparent viscosity $\left(\mu_{\mathrm{a}_{\infty}}\right)$

\begin{tabular}{lcc}
\hline & \multicolumn{2}{c}{ Type of milk } \\
\cline { 2 - 3 } Parameter & Skim & Whole \\
\hline$\lambda(\mathrm{h})$ & 2.106 & 1.762 \\
$\mu\left(\mathrm{h}^{-1}\right)$ & 0.0584 & 0.0562 \\
$\mu_{\mathrm{a} \infty}-\mu_{\mathrm{a} 0}(\mathrm{cPs})$ & 201.0 & 220.0 \\
$\mu_{\mathrm{a} 0}(\mathrm{cPs})$ & 6.43 & 6.43 \\
\hline
\end{tabular}

physicochemical changes during milk fermentation including calcium caseinate-phosphate complexes destabilization, formation of casein-denaturated whey protein linkages, and casein coagulation (Tamime and Robinson, 1999). Thus, taking into consideration that $\mathrm{pH}$ development is adequately correlated with the Gompertz model, the same model can be applied during the fermentation process to explain viscosity changes. Viscosity development interpretation according to the modified Gompertz model correspondingly illustrated the 3 major stages similar to that characterizing the acidification process: 1) lag phase (stationary viscosity), 2) logarithmic phase (rapid viscosity development), and 3 ) gel contraction; constant or slightly reduced viscosity, which are well known by previous researchers (Tamime and Robinson, 1999; Shaker et al., 2000, 2001).

Figure 3 illustrates the correlation between incubation time or viscosity and $\mathrm{pH}$. Our data suggested a linear correlation between $\mathrm{pH}$ and viscosity [Eq. 3] and incubation time [Eq. 4]. The correlations of the former parameters may furnish a useful tool for controlling the fermentation process and the viscosity development to the dairy industry, and in consequence they can be used for the determination of the end of fermentation process obtaining a high quality product by means of textural and aroma characteristics. Our data suggested a linear correlation between $\mathrm{pH}$ and viscosity [Eq. 3] and incubation time [Eq. 4]:

$$
\begin{aligned}
& \mu_{\mathrm{a}}=\mathrm{a} \ln (\mathrm{pH})+\mathrm{b} \\
& \mathrm{t}_{f}=\mathrm{c} \ln (\mathrm{pH})+\mathrm{d},
\end{aligned}
$$

where $a, b, c$, and d are constants.

Moreover, the determination of fermentation time and viscosity using the former models and their comparison to the empirically prospective values may provide information for many parameters that critically affect the fermentation process and product quality such as the activity of the lactic starter, the milk contamination with lactic acid bacteria inhibitors, the adequacy of heat treatment, and the effect of extrinsic factors such as incubation room temperature. 


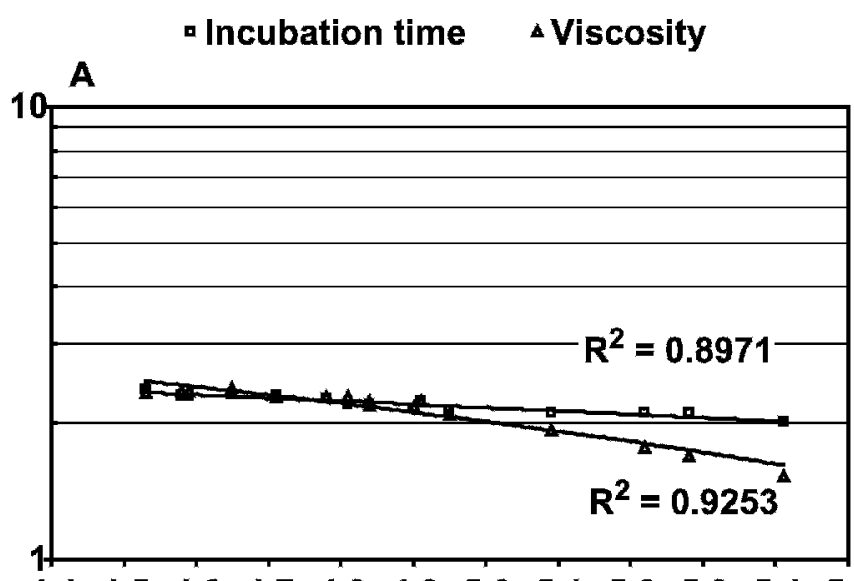

$\begin{array}{llllllllllll}4.4 & 4.5 & 4.6 & 4.7 & 4.8 & 4.9 & 5.0 & 5.1 & 5.2 & 5.3 & 5.4 & 5.5\end{array}$ B

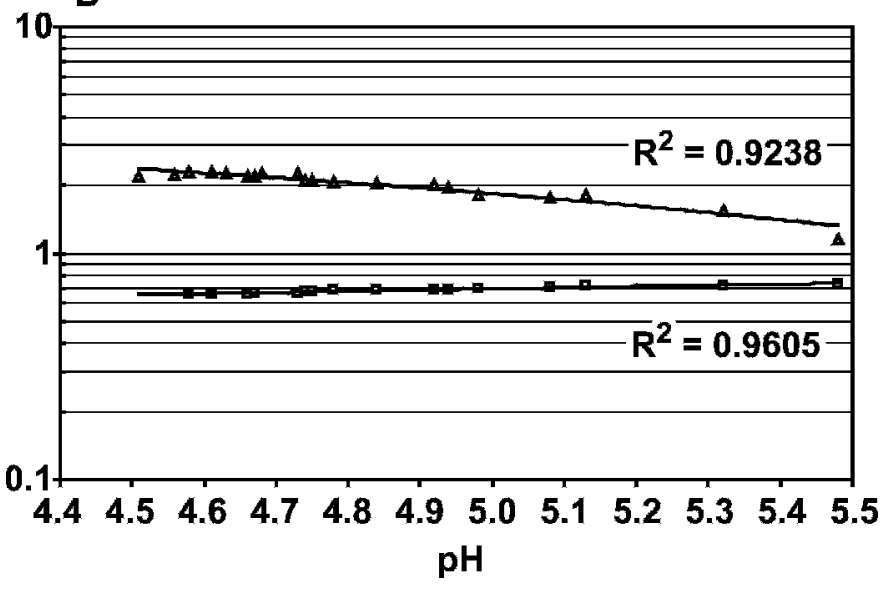

Figure 3. Correlations of incubation time ( $\mathrm{min}$ ) and viscosity (cPs $\times 10^{-1}$ ) with $\mathrm{pH}$ in yogurts prepared with $\mathrm{A}$ ) whole and B) skim milk.

Despite the convenience and the low cost of yogurt coagulation control by $\mathrm{pH}$ monitoring, the method exhibits a major problem: the drift of $\mathrm{pH}$ measuring equipment and protein deposits in the internal parts of the $\mathrm{pH}$ probe (De Brabandere and De Baerdemaeker, 1999). This problem can be curtailed by thorough cleaning and recalibration of the $\mathrm{pH}$ device at the end of the fermentation process.

The 2 major parameters ( $\mathrm{pH}$ and viscosity) may be incorporated into an automated multivariable control system. Thus, the fermentation process can be controlled continuously by monitoring both $\mathrm{pH}$ and viscosity, whereas their interaction should also be taken into consideration. Because the 2 controlled variables are each affected by both manipulations and thus, the proposed automated system should have the capability to adjust the possible declinations of the first parameter as a result of the fluctuations of the second and conversely. However, for $\mathrm{pH}$ to be used as an accurate control parameter, its correlation to the other quality characteris-

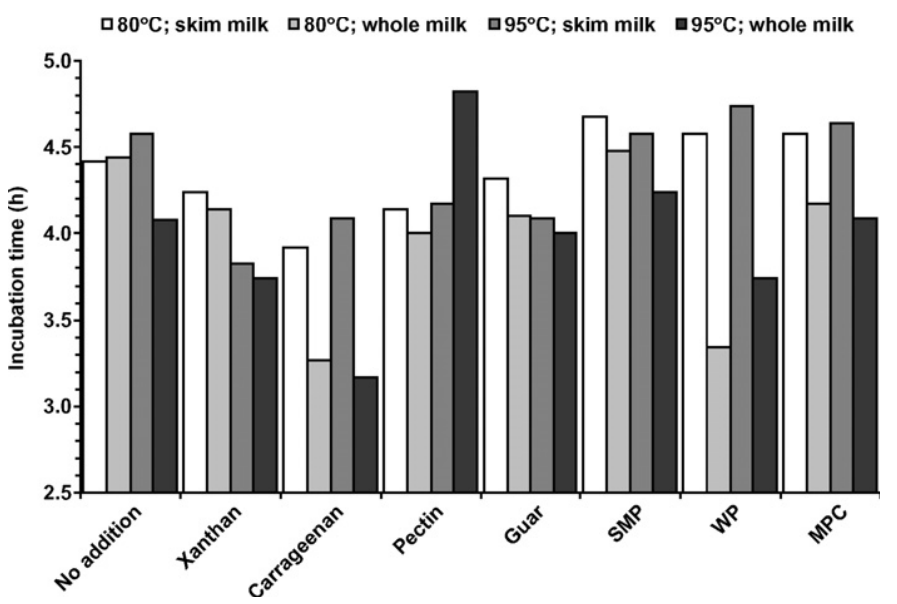

Figure 4. Effects of processing conditions (treatment at 80 or $95^{\circ} \mathrm{C}$ ) and ingredients: xanthan, $\kappa$-carrageenan, pectin, guar gum, skim milk powder (SMP), whey powder (WP), and milk protein concentrate (MPC), on the incubation time of yogurts made with whole and skim milk.

tics and also its interaction with the compositional properties of yogurt should be studied. The quality characteristics of fermented milks change very slowly after the end of the second phase of incubation. The fermentation time can be considered as the time required for $\mathrm{pH}$ to decrease down to this end point, presupposing that the required quality properties have been developed.

\section{Effect of Heat Treatment}

The effect of the heat treatment applied and compositional characteristics of milk bases on the incubation time, viscosity, acidity, and acetaldehyde concentration are displayed in Figures 4 through 7, respectively. It is well established that heat treatment implemented during yogurt manufacture affects the acidification rate and incubation time. Thus, the reduction of incubation time is due to whey protein denaturation. The greater the whey protein denaturation induced, the shorter the incubation period achieved. Our data suggested no significant effect of the applied heat treatments on incubation time (Table 4). Generally, severe heat treatment of milk base is associated with a significant decrease of incubation time (Labropoulos et al., 1981, 1984; Parnell-Clunies et al., 1988) whereas gelation phenomena commence at greater $\mathrm{pH}$ value (Lucey et al., 1999; Shaker et al., 2000). However, all heat treatments implemented in the studies mentioned above were distinctly different; that is, long time, low temperature vs. very high vat heat treatments. Moreover, in some of these studies, the effect of supplemented ingredients (SNF fortifiers or stabilizers) on the fermentation time was not taken into consideration. Our data reveal that 


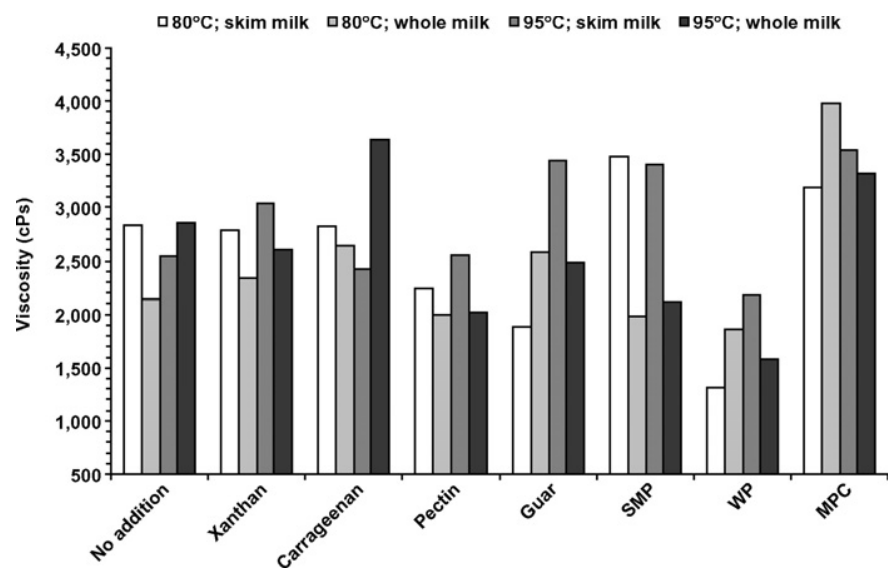

Figure 5. Effects of processing conditions (treatment at 80 or $95^{\circ} \mathrm{C}$ ) and ingredients: xanthan, $\kappa$-carrageenan, pectin, guar gum, skim milk powder (SMP), whey powder (WP), and milk protein concentrate (MPC), on the viscosity of yogurts made with whole and skim milk.

the interaction between heat treatment and supplemented ingredients (Table 4) was determined to be significant $(P<0.001)$. This supports our suggestion that the extent of the effect of heat treatment on incubation time may be enhanced or restricted depending on the milk composition (plain or enriched milk). A similar dependency can be observed for the acidities of yogurts (Figure 6) where, in general, the severely heat-treated milk formulations developed higher acidities. Milk heat treatment had a significant impact $(P<0.001)$ on viscosity (Figure 5). Yogurts fortified with xanthan gum and

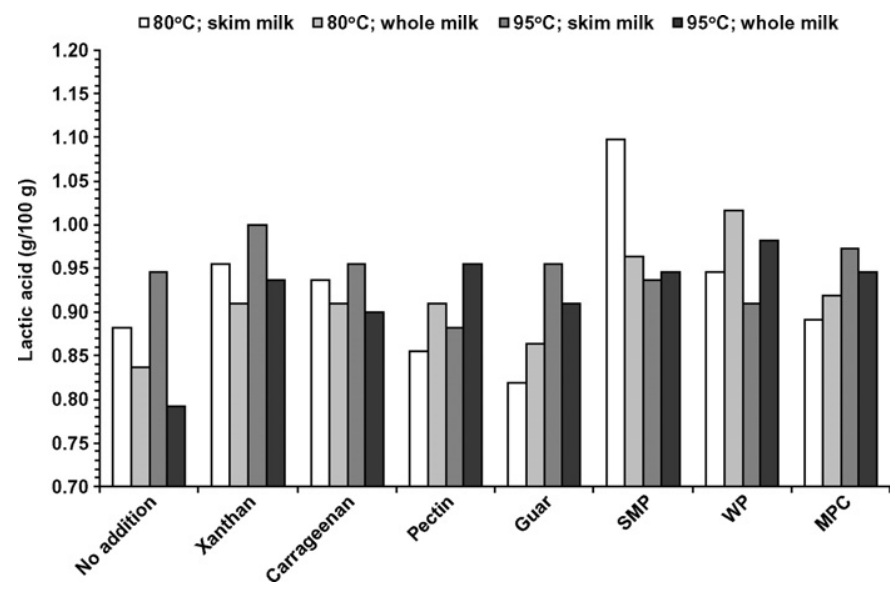

Figure 6. Effects of processing conditions (treatment at 80 or $95^{\circ} \mathrm{C}$ ) and ingredients: xanthan, $\kappa$-carrageenan, pectin, guar gum, skim milk powder (SMP), whey powder (WP), and milk protein concentrate (MPC), on the acidity of yogurts made with whole and skim milk.

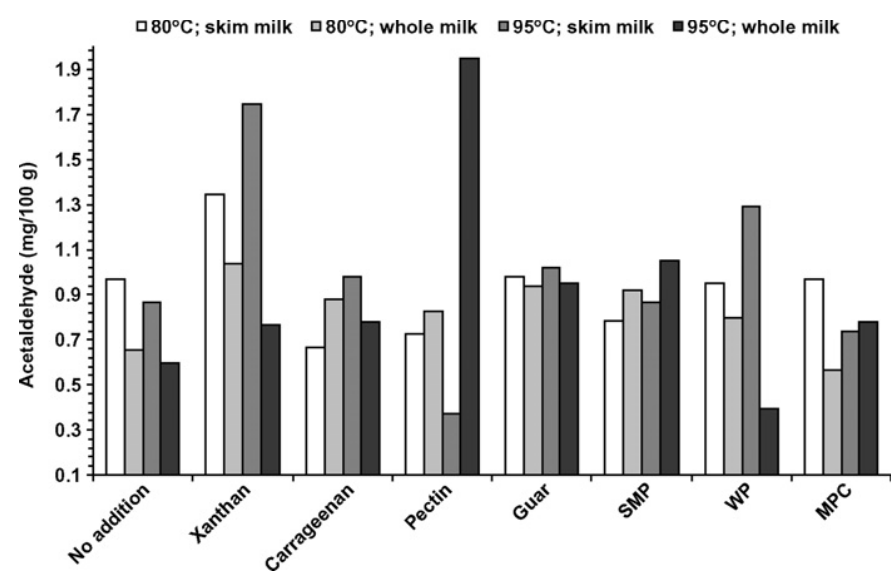

Figure 7. Effects of processing conditions (treatment at 80 or $95^{\circ} \mathrm{C}$ ) and ingredients: xanthan, $\kappa$-carrageenan, pectin, guar gum, skim milk powder (SMP), whey powder (WP), and milk protein concentrate (MPC), on the acetaldehyde concentration of yogurts made with whole and skim milk.

pectin became more viscous when the severe heat treatment was applied. The previous observation was not very clear for the other formulations. However, a more detailed investigation of the viscosity data revealed that yogurts were influenced by the interaction of heat treatment and the fat content of milk base. The viscosity of nonfat yogurts containing guar gum, WP, and MPC and whole fat yogurts with carrageenan and SMP were enhanced when the high temperature-short time heat treatment was implemented. The latter suggestion is in accordance with statistical data in Table 4. The increase in viscosity when the severe heat treatment was applied was associated with the induced formation of whey protein-casein linkages leading to gelation and texture development (Mottar et al. 1989). Both incubation time and viscosity development are influenced by heat treatment and based on the same phenomena. However, it should be considered that the incubation time is defined by $\mathrm{pH}$ (the time needed for yogurt to reach a predetermined end $\mathrm{pH}$ value) regardless of texture formation, which means that yogurts with equal incubation times may exhibit noticeably different textural properties and consequently different viscosities. Heat treatment also significantly affected $(P<0.001)$ acetaldehyde content (Figure 7). Yogurts prepared by severely heat-treated milk developed high acetaldehyde concentrations. Acetaldehyde content can be increased by performing the appropriate milk heat treatments (Tamime and Robinson, 1999).

\section{Effect of Milk Fat}

The milk fat content of yogurt significantly influenced the incubation time $(P<0.001)$, viscosity $(P<0.001)$, 
Table 4. Effects of heat treatment, milk fat, and ingredient added (addition) on incubation time and physicochemical properties of yogurts

\begin{tabular}{|c|c|c|c|c|c|c|c|c|c|}
\hline \multirow[b]{2}{*}{ Effect } & \multirow[b]{2}{*}{$\mathrm{df}$} & \multicolumn{2}{|c|}{ Incubation time } & \multicolumn{2}{|c|}{ Viscosity } & \multicolumn{2}{|c|}{ Acidity } & \multicolumn{2}{|c|}{ Acetaldehyde } \\
\hline & & MS & $F$ & MS & $F$ & MS & $F$ & MS & $F$ \\
\hline Heat treatment (HT) & 1 & 0.003 & 0.15 & 841,806 & $42.09 * * *$ & 0.00268 & 3.35 & 0.08237 & 102.96 *** \\
\hline Milk fat content (MF) & 1 & 2.088 & $104.40 * * *$ & 778,806 & $38.94 * * *$ & 0.00369 & $4.61^{*}$ & 0.11937 & $149.21^{* * * *}$ \\
\hline Addition $(\mathrm{AD})$ & 7 & 0.632 & $31.61 * * *$ & $2,094,256$ & $104.71 * * *$ & 0.01323 & $16.53^{* * *}$ & 0.17855 & $223.19 * * *$ \\
\hline $\mathrm{HT} \times \mathrm{MF}$ & 1 & 0.001 & 0.03 & 135,056 & $6.75^{*}$ & 0.00114 & 1.42 & 0.00160 & 2.00 \\
\hline $\mathrm{HT} \times \mathrm{AD}$ & 7 & 0.140 & $6.99 * * *$ & 129,035 & $6.45^{* * *}$ & 0.00622 & 7.77 *** & 0.04001 & $50.01 * * *$ \\
\hline $\mathrm{MF} \times \mathrm{AD}$ & 7 & 0.367 & $18.37 * * *$ & 655,406 & $32.77 * * *$ & 0.00732 & $9.15^{* * *}$ & 0.42279 & $528.49 * * *$ \\
\hline $\mathrm{HT} \times \mathrm{MF} \times \mathrm{AD}$ & 7 & 0.077 & 3.86 ** & 567,428 & $28.37 * * *$ & 0.00304 & $3.80 * *$ & 0.25301 & 316.26 *** \\
\hline
\end{tabular}

$* P<0.05 ; * * P<0.01 ; * * * P<0.001$.

acetaldehyde $(P<0.001)$, and acidity $(P<0.05)$. Yogurts prepared using skim milk had lower incubation rates but had greater viscosity, acetaldehyde, and lactic acid concentrations. The fortification of milk solids commonly increases the incubation time of yogurt. Our results did not demonstrate such dependence. Thomopoulos et al. (1993) reported that incubation time of yogurt was remarkably increased when whole milk was substituted by skim milk. Increased viscosity of nonfat yogurts may be attributed to higher protein content of skim milk than whole milk. Salvador and Fiszman (2004) reported that skim yogurts had greater firmness than whole fat yogurts. Sensory evaluation revealed that the use of skim milk significantly improved $(P<$ 0.001 ) all of the examined quality characteristics. Nonfat yogurts were characterized by a firm, consistent, and viscous texture. The results were in accordance with the instrumental properties. Similar results considering the texture sensory attributes have been reported by Salvador and Fiszman (2004). Moreover, nonfat yogurts exhibited enhanced flavor and they were also rated as more palatable. Brauss et al. (1999) observed that low fat yogurts $(0.2 \%$ fat) release volatiles more quickly and at higher intensity but with less persistence than whole fat yogurts.

\section{Effect of MSNF Fortifiers}

The fortification of MSNF content of milk allows the elevation of total solids to achieve a more viscous, firm, and consistent yogurt (Tamime and Robinson, 1999). The addition of $2 \%$ SMP, WP, or MPC significantly influenced $(P<0.001)$ the incubation time of yogurts (Table 5). The time required for the complete precipitation of caseins was shorter in whole milk fortified with WP than in unfortified milk or milks enriched with MPC or SMP. Puvanenthiran et al. (2002) demonstrated that the incubation time of yogurts was considerably increased when the ratio of whey protein to casein was increased, suggesting that the protein components of yogurt milk bases are an important factor determining the incubation duration. Whey powder traditionally contains a high amount of whey protein, increasing the ratio of whey proteins to caseins. However, the use of powdered protein fortifiers made using severe heat treatments (e.g., drum drying) influences parameters of yogurt fermentation such as incubation time or firmness development (Lucey et al., 1997). In our study, the WP was manufactured using a high-temperature drum-drying technique; thus, the percentage of denatured whey proteins was considerably high before the preheating of the milk base. This may explain the reduced fermentation times observed in milk bases fortified with WP. Significant reduction of the fermentation times of yogurt when whey powder was added were also reported by Penna et al. (1997).

The type of MSNF fortifier had a significant effect on the viscosity of yogurts. Yogurts containing WP were determined to be less viscous $(P<0.001)$ than those without any protein enhancement or those containing

Table 5. Effects of milk SNF fortifiers (MSNF) and milk fat on the incubation time and physicochemical properties of yogurts

\begin{tabular}{|c|c|c|c|c|c|c|c|c|c|}
\hline \multirow[b]{2}{*}{ Effect } & \multirow[b]{2}{*}{ df } & \multicolumn{2}{|c|}{ Incubation time } & \multicolumn{2}{|c|}{ Viscosity } & \multicolumn{2}{|c|}{ Acidity } & \multicolumn{2}{|c|}{ Acetaldehyde } \\
\hline & & MS & $F$ & MS & $F$ & MS & $F$ & MS & $F$ \\
\hline Heat treatment (HT) & 1 & 0.0000 & 0.00 & 70,312 & 3.52 & 0.00198 & 2.48 & 0.00003 & 0.04 \\
\hline MSNF & 7 & 0.2242 & $11.21 * * *$ & $4,225,346$ & $211.27 * * *$ & 0.02236 & $27.94 * * *$ & 0.03890 & $48.63^{* * *}$ \\
\hline $\mathrm{HT} \times \mathrm{MF}$ & 1 & 0.0392 & 1.96 & 103,512 & $5.18^{*}$ & 0.00004 & 0.05 & 0.00551 & $6.89^{*}$ \\
\hline $\mathrm{HT} \times \mathrm{MSNF}$ & 7 & 0.0783 & $3.91 * * *$ & 78,646 & $3.93^{*}$ & 0.00760 & $9.50 * * *$ & 0.01189 & $14.86^{* * *}$ \\
\hline $\mathrm{MF} \times \mathrm{MSNF}$ & 7 & 0.3348 & $16.74 * * *$ & $1,074,279$ & $53.71 * * *$ & 0.01129 & $14.11^{* * *}$ & 0.16342 & 204.27 *** \\
\hline
\end{tabular}

$* P<0.05 ; * * P<0.01 ; * * * P<0.001$. 
Table 6. Effects of milk SNF fortifiers ${ }^{1}$ and milk fat on the sensory attributes (mean values) of yogurts

\begin{tabular}{|c|c|c|c|c|c|c|c|c|}
\hline \multirow[b]{2}{*}{ Sample } & \multicolumn{8}{|c|}{ Sensory attribute } \\
\hline & Overall & Color & Aroma & Firmness & Consistency & Syneresis & Flavor & Palatability \\
\hline \multicolumn{9}{|l|}{ Skim milk } \\
\hline No addition & $7.2^{\mathrm{ef}}$ & $8.7^{\mathrm{d}}$ & $6.8^{\mathrm{abc}}$ & $7.1^{\mathrm{c}}$ & $6.9^{\mathrm{b}}$ & $3.0^{\text {cd }}$ & $6.5^{\mathrm{bc}}$ & $7.2^{\mathrm{bc}}$ \\
\hline SMP & $7.6^{\mathrm{f}}$ & $8.6^{\mathrm{d}}$ & $6.6^{\mathrm{abc}}$ & $8.2^{\mathrm{d}}$ & $7.9^{c}$ & $2.4^{\mathrm{d}}$ & $7.0^{\mathrm{c}}$ & $7.8^{\mathrm{c}}$ \\
\hline WP & $6.8^{\text {bce }}$ & $5.7^{\mathrm{ab}}$ & $6.8^{\mathrm{abc}}$ & $6.7^{\mathrm{bc}}$ & $6.4^{\mathrm{ab}}$ & $3.2^{\text {cd }}$ & $6.9^{\mathrm{c}}$ & $6.8^{\mathrm{ab}}$ \\
\hline MPC & $7.1^{\text {cef }}$ & $8.3^{\mathrm{d}}$ & $7.3^{\mathrm{c}}$ & $7.3^{\mathrm{d}}$ & $7.2^{\mathrm{b}}$ & $3.2^{\mathrm{bc}}$ & $6.9^{\mathrm{c}}$ & $7.5^{\mathrm{bc}}$ \\
\hline \multicolumn{9}{|l|}{ Whole milk } \\
\hline No addition & $6.5^{\mathrm{abc}}$ & $6.7^{\mathrm{c}}$ & $7.2^{\mathrm{bc}}$ & $6.1^{\mathrm{ab}}$ & $6.8^{\mathrm{b}}$ & $4.0^{\mathrm{ab}}$ & $6.1^{\mathrm{ab}}$ & $7.2^{\mathrm{bc}}$ \\
\hline SMP & $6.4^{\mathrm{ab}}$ & $6.2^{\mathrm{bc}}$ & $6.2^{\mathrm{a}}$ & $7.0^{\mathrm{c}}$ & $7.6^{\mathrm{c}}$ & $4.2^{\mathrm{a}}$ & $5.8^{\mathrm{a}}$ & $6.2^{\mathrm{a}}$ \\
\hline WP & $6.1^{\mathrm{a}}$ & $5.2^{\mathrm{a}}$ & $6.4^{\mathrm{ab}}$ & $6.1^{\mathrm{ab}}$ & $6.0^{\mathrm{a}}$ & $3.4^{\mathrm{abc}}$ & $6.7^{\mathrm{bc}}$ & $6.4^{\mathrm{a}}$ \\
\hline MPC & $6.0^{\mathrm{a}}$ & $6.6^{\mathrm{b}}$ & $6.4^{\mathrm{ab}}$ & $5.9^{\mathrm{a}}$ & $6.3^{\mathrm{a}}$ & $3.8^{\mathrm{ab}}$ & $6.5^{\mathrm{a}}$ & $6.5^{\mathrm{ab}}$ \\
\hline
\end{tabular}

SMP or MPC. Yogurts enriched with MPC had the highest viscosities. Similar results have been reported by Bhullar et al. (2002), Dave and Shah (1998), and Modler et al. (1983) who reported that the casein-based powders are more effective in giving firmer yogurts than are whey protein products. Penna et al. (1997) demonstrated that the optimum level of yogurt supplementation with WP ranges from 1.4 to $1.6 \%$, whereas further increases led to detrimental effects on yogurt consistency.

The acidity of yogurts containing protein fortifiers was significantly elevated compared with yogurt without additions $(P<0.001)$. Yogurts containing MPC had intermediate acidities whereas those enriched with SMP and WP had higher acidities. The elevation of titratable acidity could be due to the buffering action of the additional proteins, phosphates, citrates, lactates, and other milk constituents (Tamime and Robinson, 1999). Acetaldehyde concentration was significantly changed $(P<0.001)$ when SMP or WP was added. Acetaldehyde content was increased in the following sequence: no addition $<\mathrm{MPC}<\mathrm{SMP}<\mathrm{WP}$.
The ratings for the whole and skimmed yogurts fortified with proteins are given in Table 6 . The main effects of MSNF fortifiers are shown in Table 7. Sensory evaluation data demonstrated that the addition of whey powder improved only the flavor of yogurts. Yogurts containing WP had poor firmness and texture, were more vulnerable to syneresis, and were less palatable $(P<$ 0.001). On the other hand, only the addition of $2 \%$ SMP favored the quality properties of yogurts. Thus, yogurts fortified with SMP had enhanced firmness and consistency, good mouthfeel performance, and were less prone to syneresis. Palatability and overall acceptance were rated similarly in nonfortified yogurts and yogurts enriched with SMP. Yogurts with MPC had generally similar quality characteristics to nonfortified yogurts, although they exhibited extended syneresis. The latter effect has been reported by Guzman-Gonzalez et al. (1999).

\section{Effect of Hydrocolloids}

The primary aim of hydrocolloid addition is their ability to form linkages among themselves and with milk

Table 7. Effects of milk SNF fortifiers and milk fat on the sensory attributes of yogurts ${ }^{1}$

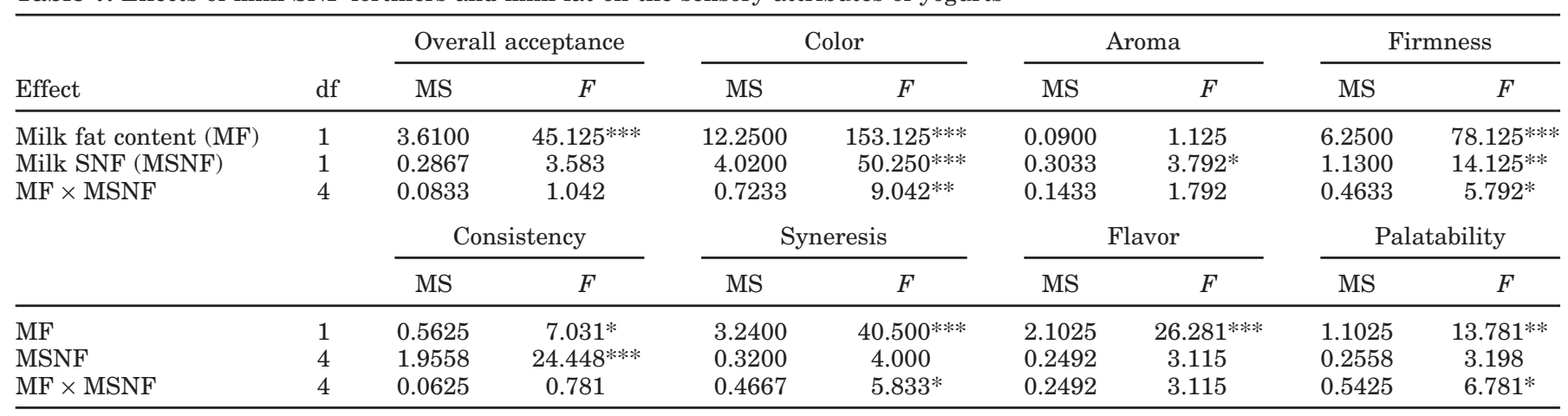

$* P<0.05 ; * * P<0.01 ; * * * P<0.001$. 
Table 8. Effects of hydrocolloids and milk fat on the incubation time and physicochemical properties of yogurts

\begin{tabular}{|c|c|c|c|c|c|c|c|c|c|}
\hline \multirow[b]{2}{*}{ Effect } & \multirow[b]{2}{*}{$\mathrm{df}$} & \multicolumn{2}{|c|}{ Incubation time } & \multicolumn{2}{|c|}{ Viscosity } & \multicolumn{2}{|c|}{ Acidity } & \multicolumn{2}{|c|}{ Acetaldehyde } \\
\hline & & MS & $F$ & MS & $F$ & MS & $F$ & MS & $F$ \\
\hline Heat treatment (HT) & 1 & 0.0176 & 0.88 & $1,115,560$ & $55.78 * * *$ & 0.01232 & $15.40^{* * *}$ & 0.10161 & $127.01 * * *$ \\
\hline Milk fat content (MF) & 1 & 0.4162 & $20.81^{* * *}$ & 158,760 & $7.94 *$ & 0.00681 & $8.52^{* *}$ & 0.00888 & $11.10 * *$ \\
\hline Hydrocolloid addition (HC) & 7 & 0.7207 & $36.04^{* * *}$ & 484,660 & $24.23^{* * *}$ & 0.00884 & $11.05^{* * *}$ & 0.24628 & $307.85 * * *$ \\
\hline $\mathrm{HT} \times \mathrm{MF}$ & 1 & 0.0020 & 0.10 & 21,160 & 1.06 & 0.00506 & $6.33^{*}$ & 0.01697 & $21.22 * * *$ \\
\hline $\mathrm{HT} \times \mathrm{HC}$ & 7 & 0.1871 & $9.36^{* * * *}$ & 102,860 & $5.14 * *$ & 0.00232 & $2.90 *$ & 0.05932 & $74.16^{* * *}$ \\
\hline $\mathrm{MF} \times \mathrm{HC}$ & 7 & 0.2819 & $14.10 * * *$ & 294,860 & $14.74 * * *$ & 0.00746 & $9.33 * * *$ & 0.60055 & $750.68 * * *$ \\
\hline $\mathrm{HT} \times \mathrm{MF} \times \mathrm{HC}$ & 7 & 0.1226 & $6.13^{* *}$ & 725,460 & $36.27 * * *$ & 0.00138 & 1.72 & 0.34598 & $432.48 * * *$ \\
\hline
\end{tabular}

$* P<0.05 ; * * P<0.01 ; * * * P<0.001$.

constituents (mainly protein particles) and bind water, resulting in viscosity enhancement, body, texture, and mouthfeel improvement (Tamime and Robinson, 1999). The addition of stabilizers significantly influenced $(P<$ 0.001 ) the incubation time (Table 8). Milks containing $\kappa$-carrageenan were characterized by shorter incubation times than those containing xanthan or guar (no significant difference among them) and pectin; the latter had the longest incubation time. It is interesting that milks without added stabilizers required much more time to reach the $\mathrm{pH}$ end point, suggesting that the interaction of hydrocolloids with proteins affected the ion equilibrium and the precipitation of caseins. Pectin was found to be the only stabilizer that did not improve viscosity. Yogurts containing xanthan and guar gum exhibited viscosities similar to those without stabilizer whereas $\kappa$-carrageenan addition led to a significant increase of viscosity. The addition of hydrocolloids in fermented milks noticeably affected $(P<0.001)$ their acidities. The former observation seems reasonable, considering that hydrocolloids carry anionic or cationic groups capable of reacting with other charged particles found in milk such as proteins or calcium ions (Tamime and Robinson, 1999). Pectin and $\kappa$-carrageenan are anionic hydrocolloids capable of interacting with positive charges on the surface of the proteins, strengthening the protein network and controlling syneresis. On the other hand, xanthan and guar gums are neutral hydrocolloids and their contribution to firmness enhancement is attributed to the increase of viscosity of the continuous phase (Hansen, 1993). Everett and McLeod (2005) demonstrated that neutral stabilizers such as guar gum and xanthan were able to improve texture over the critical percentage of $0.1 \%$, which is in accordance with our results. $\kappa$-Carrageenan exists in the form of random coils at elevated temperatures $\left(>50^{\circ} \mathrm{C}\right)$. When the temperature is lowered, the stabilizer undergoes a transition from a coil to a helix. The helix formation is accompanied by gelation phenomena and interaction with casein micelles and thereafter, it facilitates viscosity enhancement (Thomas, 1997; Langendorff et al., 2000; Spagnuolo et al., 2005). Yogurts with pectin or guar gum had higher acidities than those containing xanthan or $\kappa$-carrageenan. Similarly, the addition of stabilizers induced significant increases in acetaldehyde concentration $(P<0.001)$. The lowest acetaldehyde content was measured in nonstabilized samples whereas the highest was found in yogurts containing guar gum. Kumar and Mishra (2004) reported that the acetaldehyde content of soymilk yogurts was influenced by the addition of hydrocolloids; however, they observed that control yogurts had higher acetalde-

Table 9. Effects of hydrocolloids and milk fat on the sensory attributes of yogurts

\begin{tabular}{|c|c|c|c|c|c|c|c|c|c|}
\hline Effect & $\mathrm{df}$ & \multicolumn{2}{|c|}{ Overall acceptance } & \multicolumn{2}{|c|}{ Color } & \multicolumn{2}{|c|}{ Aroma } & \multicolumn{2}{|c|}{ Firmness } \\
\hline Milk fat content (MF) & 1 & 5.1005 & $60.361 * * *$ & 17.298 & $216.23 * * *$ & 1.0580 & $13.23^{* *}$ & 7.4420 & $93.025^{* * *}$ \\
\hline \multirow[t]{2}{*}{$\mathrm{MF} \times \mathrm{HC}$} & 4 & 0.1580 & 1.870 & 0.133 & 1.66 & 0.6280 & $7.85^{* *}$ & 0.0320 & 0.400 \\
\hline & & \multicolumn{2}{|c|}{ Consistency } & \multicolumn{2}{|c|}{ Syneresis } & \multicolumn{2}{|c|}{ Flavor } & \multicolumn{2}{|c|}{ Palatability } \\
\hline MF & 1 & 2.4500 & $30.625^{* * *}$ & 1.5680 & $19.600 * *$ & 1.5680 & $19.600 * *$ & 2.4500 & $30.62 * * *$ \\
\hline $\mathrm{HC}$ & 4 & 1.1750 & $14.687 * * *$ & 0.7730 & $9.663 * *$ & 0.6280 & $7.850 * *$ & 0.5920 & $7.40 * *$ \\
\hline $\mathrm{MF} \times \mathrm{HC}$ & 4 & 0.3850 & $4.812^{*}$ & 0.1330 & 1.663 & 0.1080 & 1.350 & 0.3200 & $4.00 *$ \\
\hline
\end{tabular}

$* P<0.05 ; * * P<0.01 ; * * * P<0.001$. 
Table 10. Effects of hydrocolloid addition and milk fat on the sensory attributes (mean values) of yogurts ${ }^{1}$

\begin{tabular}{|c|c|c|c|c|c|c|c|c|}
\hline \multirow[b]{2}{*}{ Sample } & \multicolumn{8}{|c|}{ Sensory attribute } \\
\hline & Overall & Color & Aroma & Firmness & Consistency & Syneresis & Flavor & Palatability \\
\hline \multicolumn{9}{|l|}{ Skim milk } \\
\hline No addition & $7.2^{\mathrm{e}}$ & $8.7^{f}$ & $6.8^{\mathrm{cd}}$ & $7.1^{\mathrm{d}}$ & $6.9^{\mathrm{ef}}$ & $7.0^{\mathrm{c}}$ & $6.5^{\text {cde }}$ & $7.2^{\text {def }}$ \\
\hline Pectin & $6.5^{\mathrm{cd}}$ & $8.0^{\mathrm{cd}}$ & $6.4^{\mathrm{bc}}$ & $6.9^{\mathrm{d}}$ & $5.8^{\mathrm{bc}}$ & $6.0^{\mathrm{b}}$ & $6.2^{\mathrm{bcd}}$ & $7.0^{\text {cdef }}$ \\
\hline Guar gum & $7.1^{\mathrm{de}}$ & $8.4^{\mathrm{ef}}$ & $7.2^{\mathrm{d}}$ & $6.9^{\mathrm{d}}$ & $6.9^{\text {ef }}$ & $6.2^{\mathrm{b}}$ & $6.7^{\mathrm{de}}$ & $7.3^{\mathrm{ef}}$ \\
\hline$\kappa$-Carrageenan & $6.4^{\text {cd }}$ & $7.7^{\mathrm{c}}$ & $6.7^{\text {cd }}$ & $6.2^{\mathrm{c}}$ & $6.2^{\text {cd }}$ & $5.8^{\mathrm{b}}$ & $6.0^{\mathrm{bc}}$ & $6.7^{\mathrm{cd}}$ \\
\hline Xanthan & $7.1^{\mathrm{de}}$ & $8.3^{\mathrm{def}}$ & $7.3^{\mathrm{d}}$ & $7.3^{\mathrm{d}}$ & $7.2^{\mathrm{f}}$ & $6.8^{\mathrm{c}}$ & $6.9^{\mathrm{e}}$ & $7.5^{f}$ \\
\hline \multicolumn{9}{|l|}{ Whole milk } \\
\hline No addition & $6.5^{\mathrm{cd}}$ & $6.7^{\mathrm{b}}$ & $7.2^{\mathrm{d}}$ & $6.1^{\mathrm{c}}$ & $6.8^{\mathrm{de}}$ & $6.0^{\mathrm{b}}$ & $6.1^{\text {bcd }}$ & $7.2^{\mathrm{def}}$ \\
\hline Pectin & $6.0^{\mathrm{bc}}$ & $6.7^{\mathrm{b}}$ & $6.8^{\mathrm{cd}}$ & $5.8^{\mathrm{bc}}$ & $5.8^{\mathrm{bc}}$ & $6.0^{\mathrm{b}}$ & $6.0^{\mathrm{bc}}$ & $6.8^{\mathrm{cd}}$ \\
\hline Guar gum & $5.7^{\mathrm{ab}}$ & $6.2^{\mathrm{ab}}$ & $6.0^{\mathrm{ab}}$ & $5.5^{\mathrm{ab}}$ & $5.5^{\mathrm{ab}}$ & $5.7^{\mathrm{ab}}$ & $5.7^{\mathrm{ab}}$ & $6.0^{\mathrm{ab}}$ \\
\hline$\kappa$-Carageenan & $5.1^{\mathrm{a}}$ & $5.6^{\mathrm{a}}$ & $5.7^{\mathrm{a}}$ & $5.0^{\mathrm{a}}$ & $5.1^{\mathrm{a}}$ & $5.1^{\mathrm{a}}$ & $5.2^{\mathrm{a}}$ & $5.7^{\mathrm{a}}$ \\
\hline Xanthan & $6.0^{\mathrm{bc}}$ & $6.6^{b}$ & $6.4^{\mathrm{bc}}$ & $5.9^{\mathrm{bc}}$ & $6.3^{\text {cde }}$ & $6.2^{\mathrm{b}}$ & $6.5^{\text {cde }}$ & $6.5^{\mathrm{bc}}$ \\
\hline
\end{tabular}

${ }^{a-f}$ Different letters between the rows indicates significant difference $(P<0.05)$ among the yogurts (Duncan's test).

${ }^{1}$ All hydrocolloids were added at $0.01 \%$.

hyde contents that the stabilized ones. Sensory evaluation of yogurts displayed that all the estimated attributes were significantly affected by the presence of hydrocolloids (Table 9). Sensory analysis ratings (Table $10)$ showed that the use of $\kappa$-carrageenan was inadequate because it caused deterioration in texture, mouthfeel, and palatability of yogurts. Moreover, the samples containing $\kappa$-carrageenan were found to be the most susceptible to wheying off. In general, xanthan gum had the best stabilizing effect, enhancing firmness and consistency without developing brittleness or excessive gumminess. Moreover, xanthan addition prevented the wheying off defect. The performance of xanthan gum as a means to prevent syneresis has been stated by El Sayed et al. (2002). Pectin and guar gum had similar effects on the sensory attributes examined. Apart from $\kappa$-carrageenan, stabilizers did not show significant differences among them when aroma, flavor, and color attributes were evaluated. Lo et al. (1996) reported that the addition of guar gum in yogurt at

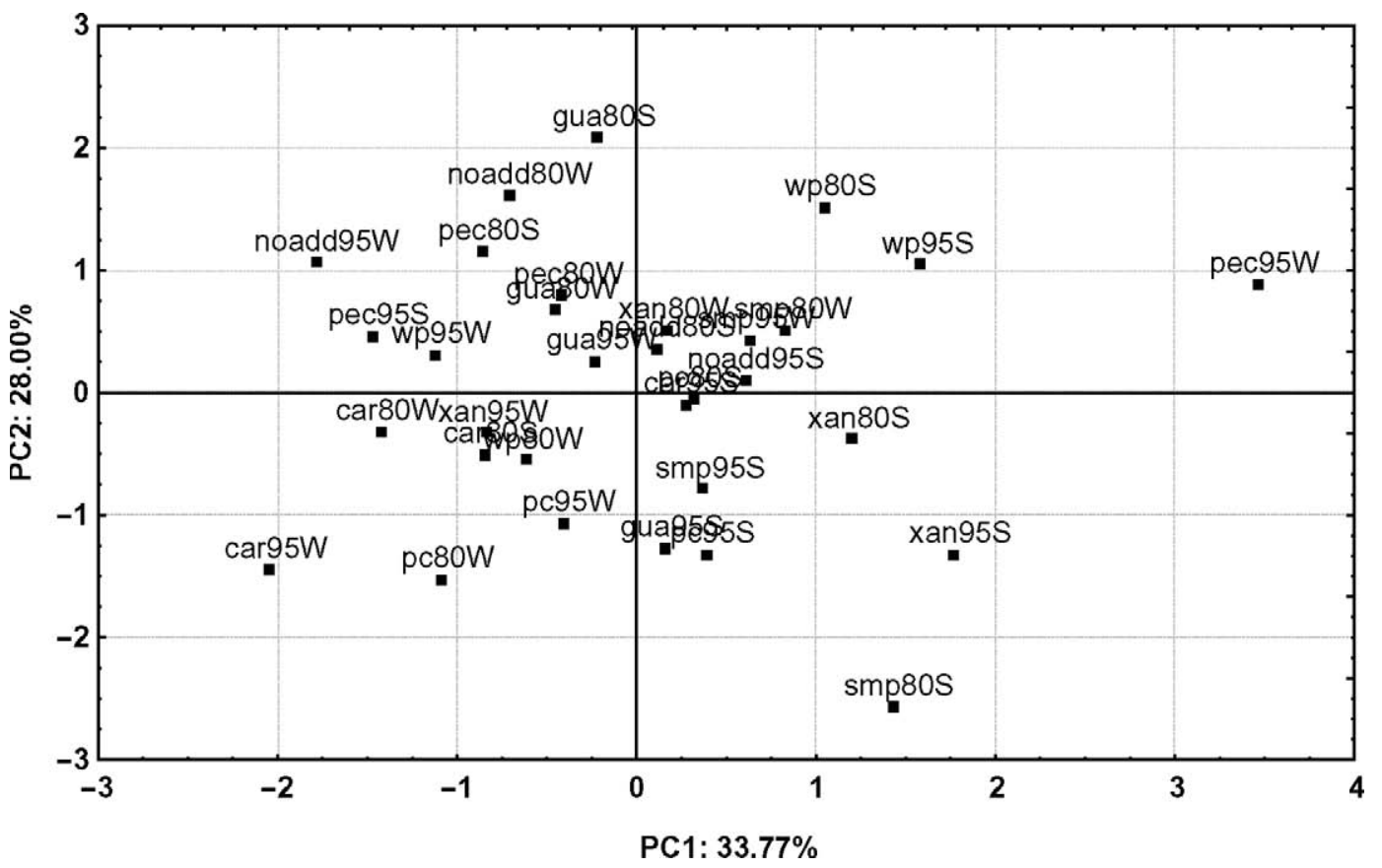

Figure 8. Principal components analysis of yogurts (physicochemical properties). Key: noadd = no addition; $x a n=x a n t h a n ;$ car $=$ carrageenan; pec $=$ pectin; gua $=$ guar gum; $\mathrm{smp}=$ skim milk powder; $\mathrm{wp}=$ whey powder; $\mathrm{pc}=$ milk protein concentrate; 80 and $95=$ heattreatment at $80^{\circ} \mathrm{C}$ and $95^{\circ} \mathrm{C}$, respectively; $\mathrm{S}=$ skim milk; $\mathrm{W}=$ whole milk. 
Table 11. Factor loadings for principal components (PC) analysis (incubation time and physicochemical properties) $^{1}$

\begin{tabular}{lrrrr}
\hline Variable & PC1 & PC2 & PC3 & \multicolumn{1}{c}{ PC4 } \\
\hline Incubation time & $\mathbf{0 . 6 5 9}$ & 0.232 & -0.619 & 0.355 \\
Viscosity & -0.153 & $\mathbf{- 0 . 7 8 6}$ & -0.542 & -0.251 \\
Acidity & 0.471 & $\mathbf{- 0 . 6 6 7}$ & 0.434 & 0.380 \\
Acetaldehyde & $\mathbf{0 . 8 1 9}$ & 0.048 & 0.148 & -0.552 \\
\hline
\end{tabular}

${ }^{1}$ Values in bold indicate the variables that load the principal components maximally.

levels ranging from 0.1 to $0.5 \%$ did not affect the release of the aroma substances. Gallardo-Escamilla et al. (2006) mentioned depression of the flavor and taste perception of fermented whey with added xanthan and high methylopectin; however, the concentrations of the hydrocolloids were substantially higher $(0.26$ and $0.53 \%$, respectively) in that study. Viscosity and firmness enhancement was significantly greater than xanthan did but less than guar.

\section{PCA}

Physicochemical and sensory properties were subjected to PCA. Sensory data were analyzed separately from the physicochemical data, because the experimental designs used for collecting them were different. The PCA plot of the yogurt samples is shown in Figure 8. The factor loadings are listed in Table 11. The first axis accounted for $33.77 \%$ of the total variance and the second for $28.00 \%$, accounting for $61.77 \%$ of the total variance. Acetaldehyde and incubation time (Table 10) were positively and maximally loaded with the first axis, whereas viscosity and acidity were negatively loaded with the second axis. As can be seen in Figure 8 , yogurts prepared using whole milk, regardless of the supplemented ingredients, were characterized by short incubation times and low acetaldehyde concentrations. Unexpectedly, there were no distinct differences in the acidities and viscosities of samples considering the milk fat content and heat treatment. The supplementation of yogurts with SMP and xanthan led to long incubation times and high acetaldehyde concentrations, whereas the addition of pectin and guar had the opposite effect. Yogurts containing MPC, xanthan, or $\kappa$-carrageenan developed the highest viscosity and acidities values.

In the PCA biplot of the severely heat-treated yogurts (Figure 9), the consistency and aroma sensory attributes were excluded because they were highly correlated with firmness and flavor attributes, respectively. The first axis accounted for $66.58 \%$ of the total variance and the second axis for $19.65 \%$, for $86.23 \%$ of total variance. The first axis was loaded negatively and maximally to overall acceptance, flavor, and firmness, and positively to syneresis. In contrast, palatability was loaded positively to the second axis. Interpreting the PCA plot, yogurts produced using skim milk exhibited

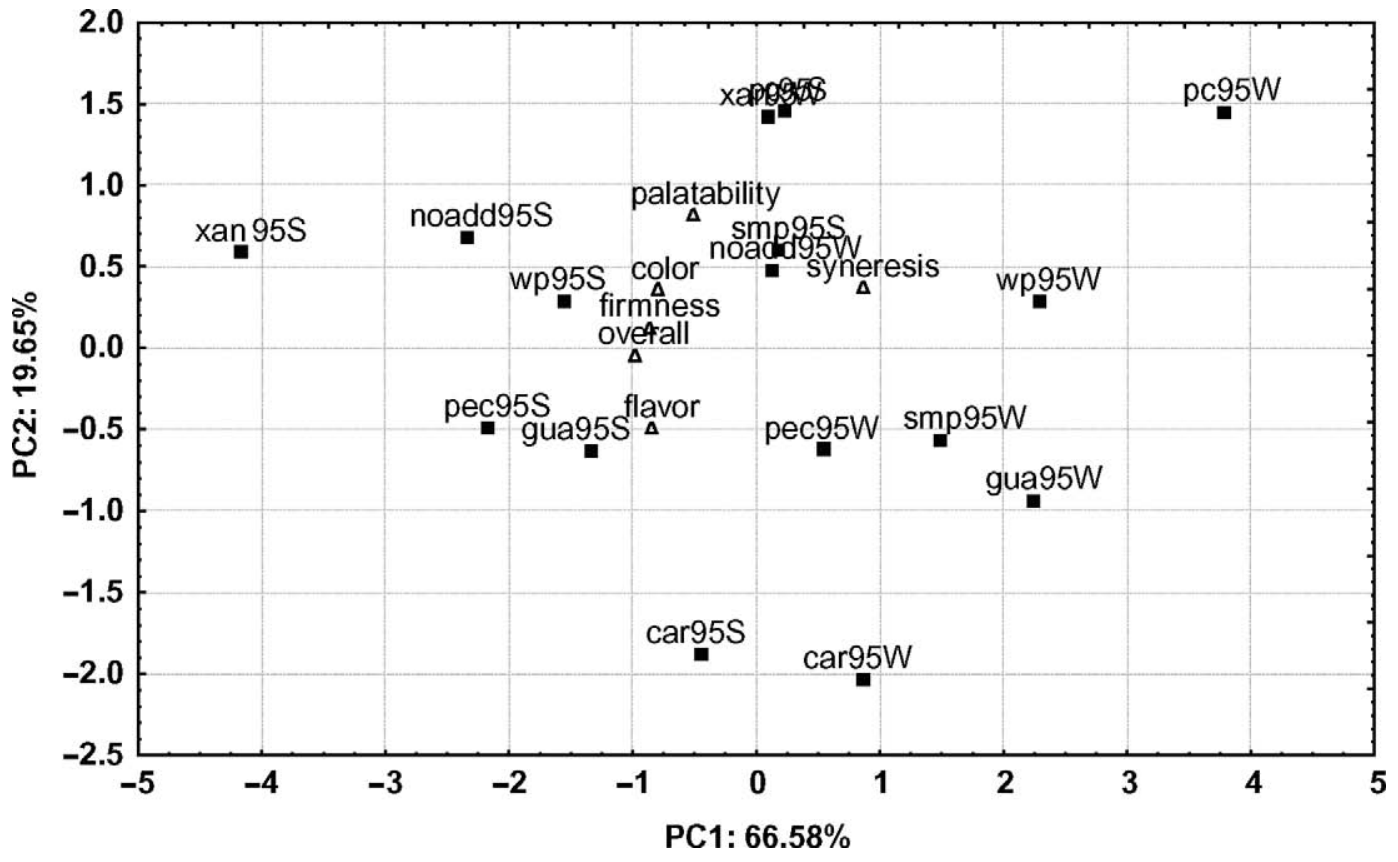

Figure 9. Principal components analysis of yogurts (selected sensory attributes). Key: noadd = no addition; xan = xanthan; car = carrageenan; pec = pectin; gua $=$ guar gum; $\mathrm{smp}=$ skim milk powder; $\mathrm{wp}=$ whey powder; $\mathrm{pc}=$ milk protein concentrate; $95=$ heat-treatment at $95^{\circ} \mathrm{C} ; \mathrm{S}=$ skim milk; $\mathrm{W}=$ whole milk. 
good textural properties, flavor, and high overall acceptance. However, skim yogurts were more susceptible to wheying off. The same defect was detected when skim milk powder was added. Surprisingly, the supplemented ingredients did not demonstrate any clear effect on the sensory profile of yogurts based on PCA analysis. Yogurts without additions or containing WP, MPC, and xanthan were determined as the most palatable samples. The results depicted by PCA seemed to be in accordance with the results discussed above.

\section{CONCLUSIONS}

The fermentation process during industrial yogurt manufacture can be continuously controlled by online monitoring of $\mathrm{pH}$, which offers a useful tool for integrated process control. The $\mathrm{pH}$-incubation time and viscosity-incubation time profiles resulting from fermentation monitoring can be used for checking product quality as well as for predictive or corrective purposes (i.e., for halting the fermentation process before operating cost and quality deterioration of the product render the overall process unprofitable). Moreover, the method is simple and requires low-cost equipment. Yogurt quality may be improved by properly selecting the parameters associated with the fermentation process and compositional properties of the milk base. The addition of $2 \%$ of protein enhancers or $0.01 \%$ of hydrocolloids was found to be adequate to affect incubation time and physicochemical and sensory properties of skimmed and whole yogurts. Addition of whey powder or $\kappa$-carrageenan caused a decrease in incubation time. Viscosity of yogurts was enhanced when milk bases were enriched with skim milk powder and $\kappa$-carrageenan. Although heat treatment of milk bases may affect the fermentation time and the physical characteristics of yogurts, the interaction of heat treatment with compositional aspects was found to be more important. Skim yogurts containing skim milk powder or xanthan gum were found to be the most acceptable samples in terms of sensory quality.

\section{ACKNOWLEDGMENTS}

We acknowledge Maria Papadaki (Chimikotechniki S.A.) for providing the hydrocolloids.

\section{REFERENCES}

Baeza, R. I., D. J. Carp, O. E. Perez, and A. M. R. Pilosof. 2002. $\kappa$ carrageenan-protein interactions: Effect of proteins on polysaccharide gelling and textural properties. Lebensm. Wiss. Technol. 35:741-747.

Bhullar, Y. S., M. A. Uddin, and N. P. Shah. 2002. Effects of ingredients supplementation on the textural characteristics and microstructure of yoghurt. Milchwissenschaft 57:328-332.
Bodyfelt, F. W., J. Tobias, and G. M. Trout. 1988. The sensory evaluation of dairy products. van Nostrand Reinhold, New York, NY.

Brauss, M. S., R. S. T. Linforth, I. Cayeux, B. Harvey, and A. J. Taylor. 1999. Altering the fat content affects flavor release in a model yogurt system. J. Agric. Food Chem. 47:2055-2059.

Cimander, C., M. Carlsson, and C. F. Mandenius. 2002. Sensor fusion for on-line monitoring of yoghurt fermentation. J. Biotechnol. 99:237-248.

Dave, R. I., and N. P. Shah. 1998. The influence of ingredient supplementation on the textural characteristics of yogurt. Aust. J. Dairy Technol. 53:180-184.

De Brabandere, A., and J. G. De Baerdemaeker. 1999. Effects of process conditions on the $\mathrm{pH}$ development during yogurt fermentation. J. Food Eng. 41:221-227.

El Sayed, E. M., I. A. Abd El Gawad, H. A. Murad, and S. H. Salah. 2002. Utilization of laboratory-produced xanthan gum in the manufacture of yogurt and soy yogurt. Eur. Food Res. Technol. 215:298-304.

Everett, D. W., and R. E. McLeod. 2005. Interactions of polysaccharide stabilizers with casein aggregates in stirred skim-milk yoghurt. Int. Dairy J. 15:1175-1183.

Fiszman, S. M., and A. Salvador. 1999. Effect of gelatine on the texture of yoghurt and of acid-heat-induced milk gels. Z. Lebensm. Unters. Forsch. 208:100-105.

Fiszman, S. M., M. A. Lluch, and A. Salvador. 1999. Effect of gelatin on microstructure of acidic milk gels and yoghurt and on their rheological properties. Int. Dairy J. 9:895-901.

Gallardo-Escamilla, F. J., A. L. Kelly, and C. M. Delahunty. 2007. Mouthfeel and flavour of fermented whey with added hydrocolloids. Int. Dairy J. 17:308-315.

Guzman-Gonzalez, M., F. Morais, and L. Amigo. 2000. Influence of skimmed milk concentrate replacement by dry dairy products in a low-fat set-type yoghurt model system. Use of caseinates, coprecipitate and blended dairy powders. J. Sci. Food Agric. 80:433-438.

Guzman-Gonzalez, M., F. Morais, M. Ramos, and L. Amigo. 1999. Influence of skimmed milk concentrate replacement by dry dairy products in a low fat set-type yoghurt model system. I: Use of whey protein concentrates, milk protein concentrates and skimmed milk powder. J. Sci. Food Agric. 79:1117-1122.

Hansen, P. M. T. 1993. Food hydrocolloids in the dairy industry. Pages 211-224 in Food hydrocolloids: Structures, properties and functions. K. Nishinari and E. Doi, ed. Plenum Press, New York, NY.

Hassan, A. N., R. Ipsen, T. Janzen, and K. B. Qvist. 2003. Microstructure and rheology of yogurt made with cultures differing only in their ability to produce exopolysaccharides. J. Dairy Sci. 86:1632-1638.

Hui, Y. H. 1993. Dairy Science and Technology Handbook. 1st ed. VCH Publishers, New York, NY.

Kalab, M., D. M. Emmons, and A. G. Sargant. 1975. Milk gel structure. IV. Microstructure of yoghurt in relation to the presence of thickening agents. J. Dairy Res. 42:453-458.

Keogh, M. K., and B. T. O'Kennedy. 1998. Rheology of stirred yogurt as affected by added milk fat, protein and hydrocolloids. J. Food Sci. 63:108-114.

Kumar, P., and H. N. Mishra. 2004. Mango soy fortified set yoghurt: Effect of stabilizer addition on physicochemical, sensory and textural properties. Food Chem. 87:501-507.

Labropoulos, A. E., W. F. Collins, and W. K. Stone. 1984. Effects of ultra-high temperature and vat processes on heat-induced rheological properties of yogurt. J. Dairy Sci. 64:405-409.

Labropoulos, A. E., A. Lopez, and J. K. Palmer. 1981. Apparent viscosity of milk and cultured yogurt thermally treated by UHT and vat systems. J. Food Prot. 44:874-876.

Langendorff, V., G. Cuvelier, C. Michon, B. Launey, A. Parker, and C. G. De Kruif. 2000. Effects of carrageenan type on the behaviour of carrageenan/milk mixtures. Food Hydrocoll. 14:273-280.

Law, A. J. R. 1996. Effect of heat treatment and acidification on the dissociation of bovine casein micelles. J. Dairy Res. 63:35-48. 
Lo, C. G., K. D. Lee, R. L. Richter, and C. W. Dill. 1996. Influence of guar gum on the distribution of some flavor compounds in acidified milk products. J. Dairy Sci. 79:2081-2090.

Lucey, J. A., P. A. Munro, and H. Singh. 1999. Effects of heat treatment and whey protein addition on the rheological properties and structure of acid skim milk gels. Int. Dairy J. 9:275-279.

Lucey, J. A., and H. Singh. 1997. Formation and physical properties of acid milk gels: A review. Food Res. Int. 30:529-542.

Lucey, J. A., C. T. Teo, P. A. Munro, and H. Singh. 1997. Rheological properties at small (dynamic) and large (yield) deformations of acid gels made from heated skim milk. J. Dairy Res. 64:591-600.

Mannheim Boehringer GmbH. 1987. Methods of Biochemical Analysis and Food Analysis. Biochemica, Mannheim, Germany.

Martin, N. C., J. Skokanova, E. Latrille, C. Beal, and G. Corrieu. 1999. Influence of fermentation and storage conditions on the sensory properties of plain low fat stirred yogurts. J. Sens. Stud. 14:139-160.

Modler, H. W., M. E. Larmond, C. S. Lin, D. Froehlich, and D. B. Emmons. 1983. Physical and sensory properties of yogurt stabilized with milk proteins. J. Dairy Sci. 66:422-429.

Mottar, J., A. Bassier, M. Joniaou, and J. Baert. 1989. Effect of heat-induced association of whey proteins and casein micelles on yogurt texture. J. Dairy Sci. 72:2247-2256.

Navratil, M., C. Cimander, and C. F. Mandenius. 2004. On-line multisensor monitoring of yogurt and filmjölk fermentations on production scale. J. Agric. Food Chem. 52:415-420.

Parnell-Clunies, E. M., Y. Kakuda, and J. M. deMan. 1986. Influence of heat treatment of milk on the flow properties of yoghurt. J. Food Sci. 51:1459-1462.

Parnell-Clunies, E. M., Y. Kakuda, J. M. deMan, and F. Cazzola. 1988. Gelation profiles of yogurt as affected by heat treatment of milk. J. Dairy Sci. 71:582-588.
Penna, A. L. B., R. Barrufaldi, and M. N. Oliveira. 1997. Optimization of yogurt production using demineralized whey. J. Food Sci. $62: 846-850$

Puvanenthiran, A., R. P. W. Williams, and M. A. Augustin. 2002. Structure and visco-elastic properties of set yoghurt with altered casein to whey protein ratios. Int. Dairy J. 12:383-391.

Ramaswamy, H. S., and S. Basak. 1992. Pectin and raspberry concentrate effects on the rheology of stirred commercial yogurt. J. Food Sci. 57:357-360.

Salvador, A., and S. M. Fiszman. 2004. Textural and sensory characteristics of whole and skimmed flavored set type yogurt during long storage. J. Dairy Sci. 87:4033-4041.

Schkoda, P., A. Hechler, and J. Hinrichs. 2001. Influence of the protein content on structural characteristics of stirred fermented milk. Milchwissenschaft 56:19-22.

Shaker, R. R., B. Abu-Jdayil, R. Y. Jumah, and S. A. Ibrahim. 2001. Rheological properties of set yogurt during gelation process: II. Impact of incubation temperature. Milchwissenschaft 56:622625.

Shaker, R. R., R. Y. Jumah, and B. Abu-Jdayil. 2000. Rheological properties of plain yogurt during coagulation process: Impact of fat content and preheat treatment of milk. J. Food Eng. 44:175-180.

Spagnuolo, P. A., D. G. Dalgleish, H. D. Goff, and E. R. Morris. 2005. Kappa-carrageenan interactions in systems containing casein micelles and polysaccharide stabilizers. Food Hydrocoll. 19:371-377.

Tamime, Y. A., and R. K. Robinson. 1999. Yoghurt: Science and Technology. 2nd ed. Woodhead Publishing Ltd., Cambridge, UK.

Thomas, W. R. 1997. Carrageenan. Pages 45-59 in Thickening and Gelling Agents for Food. 2nd ed. Blackie Academic and Professional, London, UK.

Thomopoulos, C., C. Tzia, and D. Milkas. 1993. Influence of processing of solids-fortified milk on coagulation time and quality properties of yogurt. Milchwissenschaft 48:426-430. 